\title{
Unmet Healthcare Needs Among Elderly Malaysians [Corrigendum]
}

Shah SA, Safian N, Ahmad S, et al. J Multidiscip Healthc. 2021;14:2931-2940.

The authors have advised there was misuse of the word "elderly" in the title and some sentences within the main text. Additionally, the Ethics Approval and Funding sections have also been updated.

The paper title should read from "Unmet Healthcare Needs Among Elderly Malaysians" to "Unmet Healthcare Needs Among Older Malaysians".

On page 2935, second paragraph from the right column, the first sentence should read from "This study found that overweight and obese elderly more likely to have unmet healthcare needs than the non-obese elderly." to "This study found that overweight and obese older people are more likely to have unmet healthcare needs than the non-obese older people."

On page 2935, second paragraph from the right column, the last sentence should read from "Regardless, cautious interpretation of BMI in the elderly is necessary because lean body mass, fat mass, or fluid retention are not determinants of BMI, ${ }^{22,26}$ and aging is associated with progressive loss of muscle strength, mass, and increased fat mass. 19,27 " to "Regardless, cautious interpretation of BMI in older people is necessary because lean body mass, fat mass, or fluid retention are not determinants of BMI, ${ }^{22,26}$ and aging is associated with progressive loss of muscle strength, mass, and increased fat mass. ${ }^{19,27,}$

On page 2937 , last sentence on the left column should read from "The inability of the elderly to travel alone therefore needs attention in collaboration with the community or nearby nongovernmental agencies to provide these older people with transportation assistance to reach nearby health facilities." to "The inability of older people to travel alone therefore needs attention in collaboration with the community or nearby nongovernmental agencies to provide these older people with transportation assistance to reach nearby health facilities."

On page 2938, in the Ethics Approval section, the last sentence should read from "This research was approved by the Research Ethics Committee of the National University of Malaysia (FF-2018-532;14 September 2018)." to "This research was approved by the Research Ethics Committee of the National University of Malaysia (FF-2018532;14 September 2018) and the Research Ethics Review Committee of the World Health Organization (ERC.0003072; 17 September 2018)."

On page 2939, in the Funding section, it should read from "This research was funded by the World Health Organization Centre for Health Development (WHO Kobe Centre-WKC) grant number 2018/863819-1. The funder had no role in the study's design; in the data collection; analyses, or interpretation data; in the writing of the manuscript; or in the decision to publish the results." to "This research was funded by the World Health Organization Centre for Health Development (WHO Kobe Centre-WKC:K18015). The funder had a role in the study's design and in the decision to publish the results; it had no role in the data collection, analyses, or interpretation of data, nor in the writing of the manuscript. The views and opinions expressed in the document are solely the responsibility of the authors and do not necessarily represent the official views or positions of the World Health Organization."

The authors apologize for these errors. 


\section{Publish your work in this journal}

The Journal of Multidisciplinary Healthcare is an international, peerreviewed open-access journal that aims to represent and publish research in healthcare areas delivered by practitioners of different disciplines. This includes studies and reviews conducted by multidisciplinary teams as well as research which evaluates the results or conduct of such teams or healthcare processes in general. The journal covers a very wide range of areas and welcomes submissions from practitioners at all levels, from all over the world. The manuscript management system is completely online and includes a very quick and fair peer-review system. Visit http://www.dovepress.com/testimonials. php to read real quotes from published authors.

Submit your manuscript here: https://www.dovepress.com/journal-of-inflammation-research-journal 